\title{
Self-assembled mono- and bilayers on gold electrodes to assess antioxidants-a comparative study
}

\author{
Mehdi Ravandeh $^{1}$ (D) Dana Thal ${ }^{1}$ (D) $\cdot$ Heike Kahlert $^{1}$ (D) $\cdot$ Kristian Wende $^{2}$ (D) Michael Lalk $^{1}$ (D)
}

Received: 30 April 2020 / Revised: 19 June 2020 / Accepted: 19 June 2020 / Published online: 2 July 2020

(C) The Author(s) 2020

\begin{abstract}
Oxidative stress is considered as an imbalance of reactive species over antioxidants, leading to diseases and cell death. Various methods have been developed to determine the antioxidant potential of natural or synthetic compounds based on the ability to scavenge free radicals. However, most of them lack biological relevance. Here, a gold-based self-assembled monolayer (SAM) was compared with a gold-supported lipid bilayer as models for the mammalian cell membrane to evaluate the free radical scavenging activity of different antioxidants. The oxidative damage induced by reactive species was verified by cyclic and differential pulse voltammetry and measured by the increase of electrochemical peak current of a redox probe. Trolox, caffeic acid (CA), epigallocatechin gallate (EGCG), ascorbic acid (AA), and ferulic acid (FA) were used as model antioxidants. The change in the decrease of the electrochemical signal reflecting oxidative membrane damage confirms the expected protective role. Both model systems showed similar efficacies of each antioxidant, the achieved order of radical scavenging potential is as follows: Trolox $>$ CA $>$ EGCG $>$ AA $>$ FA. The results showed that the electrochemical assay with SAM-modified electrodes is a stable and powerful tool to estimate qualitatively the antioxidative activity of a compound with respect to cell membrane protection against biologically relevant reactive species.
\end{abstract}

Keywords Electrochemical assay $\cdot$ Reactive species $\cdot$ Radical scavenging activities $\cdot$ SAM $\cdot$ Lipid bilayer $\cdot$ Antioxidant activity

\section{Introduction}

Redox biology plays an important role in healthy or diseased cell function [1]. The cellular redox systems were found to be more complex than first anticipated, but its modulation by antioxidants is assumed to hold potential for the prevention or treatment of degenerative diseases [2, 3]. For example, the naturally occurring polyphenol kaempferol has been suggested to hold some potential for the clinical application in both tumor prevention and therapy [4]. Another example is Gypenosides, the main components from Gynostemma

The authors dedicate this work to Professor Fritz Scholz on the occasion of his 65 th birthday.

Heike Kahlert

hkahlert@uni-greifswald.de

1 Institute of Biochemistry, University of Greifswald, Felix-Hausdorff-Str. 4, 17489 Greifswald, Germany

2 Leibniz-Institute for Plasma Science and Technology, ZIK Plasmatis, Felix-Hausdorff-Str. 2, 17489 Greifswald, Germany pentaphyllum Makino, a plant widely used in traditional Chinese medicine, which has been attributed to anti-cancer effects [5]. However, even though a great variety of approaches to assess the antioxidant activity of plant compounds or extracts exists, its informative value for biological systems is often limited. Highly artificial in vitro antioxidant assays are tools often applied in the food industry or for compound screening purposes. They mainly focus on the ability of a substance to neutralize or reduce the number of active radicals in a system. From a mechanistic point of view, the common assays can basically be divided into two main groups: assays that rely on electron transfer reaction (ET) and assays that are based on hydrogen atom transfer (HAT) reactions [6]. Popular examples for ET assays are as follows: TEAC (Trolox equivalent antioxidant capacity) [7], FRAP (ferric ion reducing/ antioxidant power) [8], DPPH (1,1-diphenyl-2picrylhydrazyl) reduction capacity assay [9], $p$-NDA $(N, N$ dimethyl-4-nitrosoaniline) oxidation assay [10], PCL assay (photo chemiluminescence) [11], the DMPD ( $N, N$-dimethyl$p$-phenylendiamine) assay [12], or the total phenol assay by Folin-Ciocalteu reagent. Among the HAT assay are the ORAC (oxygen radical absorbance capacity) [13], the crocin 
bleaching method [14], inhibition of lipid oxidation, and the TRAP (total radical trapping antioxidant parameter) [15]. Most of them measure the reaction of a target substance with a radical. In some cases, like in the DPPH assay, they are rather stable artificial radicals that have no biological relevance. Other shortcomings that make it difficult to obtain biological relevant data are non-physiological $\mathrm{pH}$ values or the absence of complex reaction media that could affect reactions in vivo.

Electrochemical methods offer the possibility to investigate the antioxidant capacity of natural or synthetic substances in four ways. First, the antioxidant potential of a substance can be evaluated by the determination of the redox properties at relevant $\mathrm{pH}$ values [16]. It is a valuable tool for a quick screening; however, the obtained potentials depend on the selection of the electrolyte. Therefore, the predictive value for biological systems is often limited. The second option is to determine the interaction of reactive species in general, or as a third option reactive species that play a role in human redox systems, like reactive oxygen species (ROS), with a potential antioxidant and follow the reaction with electrochemical methods like cyclic voltammetry [16-19]. However, since it is only a two-component system, the results cannot be compared with the activity of such antioxidants in vivo.

The fourth option is to use systems that model biological or biochemical effects, i.e., sensor systems for ROS detection, utilizing the antioxidants capacity to reduce the ROS concentration and decrease the effect of ROS on the model system. One class of sensors relies on enzymes that are immobilized on the electrode surface, e.g., cytochrome c [20, 21] and superoxide dismutase (SOD) [22, 23]. However, using these sensors, specific experimental conditions that enable proper enzyme activity (e.g., $\mathrm{pH}$, temperature, right location of the active center) are required. Other sensors that concentrate on the interaction of ROS with DNA use immobilized doublestranded DNA. Scholz et al. [24] developed an electrochemical assay to quantify oxygen radicals. Here, gold electrodes are modified with a self-assembled monolayer (SAM) that is degraded upon exposure to oxygen radicals proportional to their concentration and exposure time. The extent of damage of the SAM can be assessed by voltammetric techniques in an electrolyte containing a redox probe such as $\mathrm{Ru}\left(\mathrm{NH}_{3}\right)_{6}^{3+/ 2+}$ or $\left[\mathrm{Fe}(\mathrm{CN})_{6}\right]^{3-/ 4-}$. It has been demonstrated that the electrochemical assay can be used to determine antioxidative activities of plant extracts [25], as the scavenging activity is reflected in the inhibition of the SAM degradation. The main advantage of the method is the easy preparation of the SAM and that the interaction of biologically relevant radicals with SAMs as well as with antioxidants can be measured. As expected, the assays rank the antioxidant potential of individual substances differently from established antioxidant assays. Nevertheless, the question remains how efficient the antioxidant activity of a substance is in terms of protecting a particular target molecule/structure such as a cell membrane. Here, supported lipid bilayers can provide a valuable in vitro platform for the investigation of a variety of biological questions associated with cell membrane function, structure, and composition.

In the current study, to mimic the biological system, a goldsupported lipid bilayer was used as a model for cell membrane, and cold physical plasma jet (kINPen®) was used for the formation of a mixture of biologically relevant reactive species. A gold-supported lipid bilayer of 1-palmitoyl-2oleoyl-sn-glycero-3-phosphocholine (POPC) was prepared by the potential cycle assisted vesicle fusion method [26, 27]. The bilayer was exposed to reactive species generated by cold physical plasma jet ( $\mathrm{kINPen} \circledast)$ in the presence and absence of different antioxidants, and electrochemical measurements were performed to follow the degradation of the bilayer. The obtained ranking of the antioxidant activity of four model substances as well as the concentration dependence of the protective action was compared with the results obtained with a SAM-modified electrode which was exposed to radicals produced by photolysis of $\mathrm{H}_{2} \mathrm{O}_{2}$ in presence and absence of the same compounds. By finding no significant difference in the outcome of the two assays, SAM-modified electrodes with electrochemical detection are powerful tools to estimate qualitatively the antioxidative activity of a compound with respect to cell membrane protection.

\section{Experimental}

\section{Chemicals}

Dry powder of 1-palmitoyl-2-oleoyl-sn-glycero-3phosphocholine (POPC) was from Avanti Polar Lipids. Chloroform, ethanol, 1-decanethiol, $\left[\mathrm{Ru}\left(\mathrm{NH}_{3}\right)_{6}\right] \mathrm{Cl}_{3}$, ascorbic acid (AA), and (-)-epigallocatechin gallate (EGCG) were purchased from Sigma-Aldrich. Trolox (6-hydroxy-2,5,7,8tetramethylchroman-2-carboxylic acid, $97 \%$ ) was from Acros Organics. Potassium ferrocyanide $\left(\mathrm{K}_{4}\left[\mathrm{Fe}(\mathrm{CN})_{6}\right]\right)$, $\mathrm{Na}_{2} \mathrm{HPO}_{4}, \mathrm{NaH}_{2} \mathrm{PO}_{4}, \mathrm{H}_{2} \mathrm{SO}_{4}, \mathrm{H}_{2} \mathrm{O}_{2}(30 \%)$, acetic acid, and sodium acetate were obtained from Merck. Caffeic acid (CA, $98 \%$ ) was purchased from Roth. All chemicals employed were used without further purification. All solutions were prepared using ultrapure water (resistivity $=18.2 \mathrm{M} \Omega / \mathrm{cm}$ ).

\section{Electrode preparation}

Polycrystalline Au electrodes (Ø $2 \mathrm{~mm}$; Metrohm) served as working electrodes. Before modification with self-assembled mono- or bilayers, the surface must be cleaned in order to get an ultra-flat surface. This was done based on the protocol by Thal et al. [28]. Briefly, electrodes were mechanically 
polished with $\mathrm{Al}_{2} \mathrm{O}_{3}$ powder (Buehler; grain sizes 300 and 50 $\mathrm{nm}$ ) and loosely attached alumina particles were removed in ultrasonic bath. Afterwards, electrodes were cycled from 0 to $1.5 \mathrm{~V}$ in $0.1 \mathrm{M} \mathrm{H}_{2} \mathrm{SO}_{4}$ at $0.1 \mathrm{~V} \mathrm{~s}^{-1}$ until a stable voltammogram was obtained $(40 \pm 10$ cycles to obtain stable voltammogram). Au oxides were removed from the surface by additional 10 cycles in $0.1 \mathrm{M} \mathrm{H}_{2} \mathrm{SO}_{4}$ from 0.75 to $0.2 \mathrm{~V}$ at $0.1 \mathrm{~V}$ $\mathrm{s}^{-1}$

\section{SAM formation}

The cleaned gold electrodes were rinsed with water and ethanol and immersed into $2 \mathrm{mM}$ ethanolic 1-decanethiol solution and kept at room temperature in the dark for $17 \mathrm{~h}$. After the SAM formation process, the electrodes were again rinsed with water and ethanol. The integrity of the formed SAM was tested in differential pulse voltammetry (DPV) measurements in $1 \mathrm{mM}\left[\mathrm{Ru}\left(\mathrm{NH}_{3}\right)_{6}\right] \mathrm{Cl}_{3}$ solution in $0.1 \mathrm{M}$ acetate buffer $(\mathrm{pH}=$ 4.7). The coating procedure was assumed successful in the case of the absence of the $\mathrm{Ru}\left(\mathrm{NH}_{3}\right)_{6}^{3+}$ reduction signal.

\section{Bilayer formation}

Bilayer formation was done by potential assisted vesicle fusion method [26]. Briefly, POPC liposomes were prepared by sonication. The desired amount of lipid was dissolved in chloroform. The solvent was evaporated under a constant stream of nitrogen yielding a homogenous lipid film. Remaining traces of solvent were removed by placing the samples under vacuum overnight. The lipid film was thereafter suspended in deaerated $50 \mathrm{mM}$ phosphate buffer ( $\mathrm{pH}$ 7.4) and sonicated with a tip-sonicator for $45 \mathrm{~min}$ in ice yielding small unilamellar vesicles (SUVs). Afterwards, the suspension was centrifuged for $10 \mathrm{~min}$ at $14,000 \mathrm{rpm}$ to remove titanium debris of the sonication procedure.

The size distribution of the obtained SUVs was measured by dynamic light scattering (DLS) using a NICOMP 380 Particle Sizer (Particle Sizing Systems). The final lipid concentration in the samples was $0.5 \mathrm{mg} \mathrm{mL}^{-1}$.

Lipid bilayer on the gold surface was formed by slow potential scans $\left(5 \mathrm{mV} \mathrm{s}^{-1}\right.$ cycling between 0.4 and $-0.8 \mathrm{~V}$ vs $\mathrm{Ag} / \mathrm{AgCl}$ for at least $4 \mathrm{~h}$ ) after the addition of the liposome suspension to the electrochemical cell. After the formation of the lipid bilayer on gold electrode, the remaining liposome suspension in the cell was replaced by buffer and water for further experiments.

\section{Radical treatment}

Reactive oxygen and nitrogen species were generated either by a cold physical plasma source, the kINPen ${ }^{\circledR}$ (neoplas), or by UV photolysis (Metrohm). The plasma jet consists of a central pin-type electrode powered by a voltage of $2-6 \mathrm{kV}$ with a frequency of $1 \mathrm{MHz}$. Argon was used as feed gas (3 standard 1/min) [29]. For all experiments with the kINPen®, a direct treatment regimen was chosen and achieved by exposing $10 \mathrm{~mL}$ of water-covered solid-supported lipid bilayer to the plasma effluent at a distance of $9 \mathrm{~mm}$ to the aqueous surface. Radical exposure of SAM-modified electrodes was performed in quartz test tubes (Metrohm) filled with $10 \mathrm{~mL}$ of $1 \mathrm{mM} \mathrm{H} \mathrm{H}_{2} \mathrm{O}_{2}$. Radicals were generated by photolysis of $\mathrm{H}_{2} \mathrm{O}_{2}$ by UV light radiation (705 UV Digester, Metrohm). The electrodes were exposed to the formed radicals for treatment intervals of $30 \mathrm{~s}$.

\section{Electrochemical measurements}

All electrolytes were deaerated before electrochemical measurements (600-s nitrogen purging prior to measurement). The voltammetric measurements were performed with a 663 VA stand in combination with an Autolab PGSTAT 20 and Eco Chemie IME 303 (Metrohm). The modified gold electrode served as the working electrode, a platinum electrode as the counter electrode, and an $\mathrm{Ag} / \mathrm{AgCl}(3 \mathrm{M} \mathrm{KCl})$ electrode as the reference. Data were recorded with NOVA 2.0 software (Metrohm). Data analysis was performed with OriginPro 2016 (OriginLab Cooperation). As electrolyte, either $10 \mathrm{mM}$ solution of $\mathrm{K}_{4}\left[\mathrm{Fe}(\mathrm{CN})_{6}\right]$ in $50 \mathrm{mM}$ phosphate buffer $(\mathrm{pH} 7.4)$ or $1 \mathrm{mM}\left[\mathrm{Ru}\left(\mathrm{NH}_{3}\right)_{6}\right] \mathrm{Cl}_{3}$ in $0.1 \mathrm{M}$ acetate buffer $(\mathrm{pH}=4.7)$ was used. Cyclic and differential pulse voltammograms of $\mathrm{K}_{4}\left[\mathrm{Fe}(\mathrm{CN})_{6}\right]$ were recorded in the potential range from -0.3 to $+0.7 \mathrm{~V}$ vs. $\mathrm{Ag} / \mathrm{AgCl}$ and $50 \mathrm{mV} \mathrm{s}^{-1}$ as a scan rate. Differential pulse voltammograms of $\left[\mathrm{Ru}\left(\mathrm{NH}_{3}\right)_{6}\right] \mathrm{Cl}_{3}$ were recorded in the potential range from +0.3 to $-0.7 \mathrm{~V}$ vs. $\mathrm{Ag} /$ $\mathrm{AgCl}$

\section{Results and discussion}

Gold electrodes covered with a 1-decanethiol SAM showed a complete suppression of the reduction signal of the redox probe $\mathrm{Ru}\left(\mathrm{NH}_{3}\right)_{6}^{3+}$, as it is shown in Fig. 1. We used the $\mathrm{Ru}$ $\left(\mathrm{NH}_{3}\right)_{6}^{3+} / \mathrm{Ru}\left(\mathrm{NH}_{3}\right)_{6}^{2+}$ as the redox probe in these experiments, since it undergoes a simple charge transfer process with a high rate constant, as was shown by Wilke et al. [30]. A treatment with ROS produced via UV photolysis of $\mathrm{H}_{2} \mathrm{O}_{2}$ altered the SAM structure in a way that the redox probe can penetrate the SAM, and the reduction signal is regained. However, the initial current maximum of the bare gold electrode was not regained after ROS treatment up to $50 \mathrm{~min}$ (Fig. 1). Previous experiments with hexacyanoferrate(II) as redox probe and hexanethiol, $\mathrm{C}_{6} \mathrm{SH}$, demonstrated that a complete removal of the SAM with hydroxyl radical generated by Fenton reaction could not be achieved. Since the ROS 


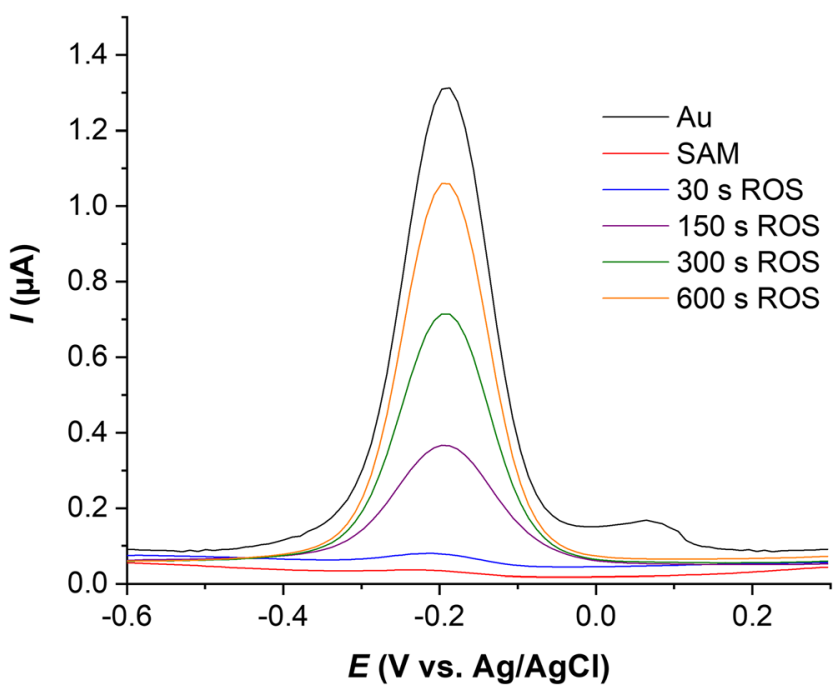

Fig. 1 DPV measurements in $1 \mathrm{mM}\left[\mathrm{Ru}\left(\mathrm{NH}_{3}\right)_{6}\right] \mathrm{Cl}_{3}$ solution in $0.1 \mathrm{M}$ acetate buffer $(\mathrm{pH}=4.7)$. Black line: bare gold electrode before SAM preparation; red line: gold electrode covered with $\mathrm{C}_{10} \mathrm{SH}$ SAM; blue, purple, green, and orange line: gold electrode covered with $\mathrm{C}_{10} \mathrm{SH}$ SAM after $30-\mathrm{s}, 150$-s, $300-\mathrm{s}$, and 600 -s exposure time to photolytically produced ROS

concentrations in our experiments were even lower, we assumed that complete SAM removal by the generated ROS cannot be expected. Therefore, the active electrode surface remains below the initial surface area resulting in a lower maximum reduction current measured at the electrodes after 10-min ROS treatment. Nonetheless, until this time point a gradual increase of the reduction signal correlating with the ROS treatment time is recorded at the electrodes (Fig. 1). This suggests that ROS induced damages to the SAM, which might lead to the removal of thiol molecules from the gold surface as well as rearrangements of the alkyl chains, are irreversible and that even though reorganization events of the remaining thiol molecules on the gold surface might occur, the extent of exposed active gold sites is proportional to the time of ROS exposure. Previous studies with AFM have shown that thiol molecules are removed from the surface resulting in holes within the layer. However, we cannot prove that the Au-S bond specifically is broken [28].

Hilgemann et al. [25] employed the electrochemical assay to measure the radical scavenging capacity of plant extracts. For data evaluation, they plotted the logarithm of the standardized DPV peak currents against the radical treatment time $\left(\ln \left(1-\left[i / i_{0}\right]\right)\right.$ vs. $t ; i_{0}$ is the peak current for the bare gold electrode). For the resulting function, they obtained two distinct linear sections describing the exponential decay of the curve: a fast decay from 0 to $5 \mathrm{~min}$ and a slower decay from 5 to $30 \mathrm{~min}$. The kinetic constant of the second decay decreases in the presence of antioxidants and the evaluation of this kinetic constant can be used to estimate antioxidant capacity. Figure 2 shows the logarithmic increase of the $\mathrm{Ru}\left(\mathrm{NH}_{3}\right)_{6}^{3+}$ reduction signal in dependence of the treatment time under

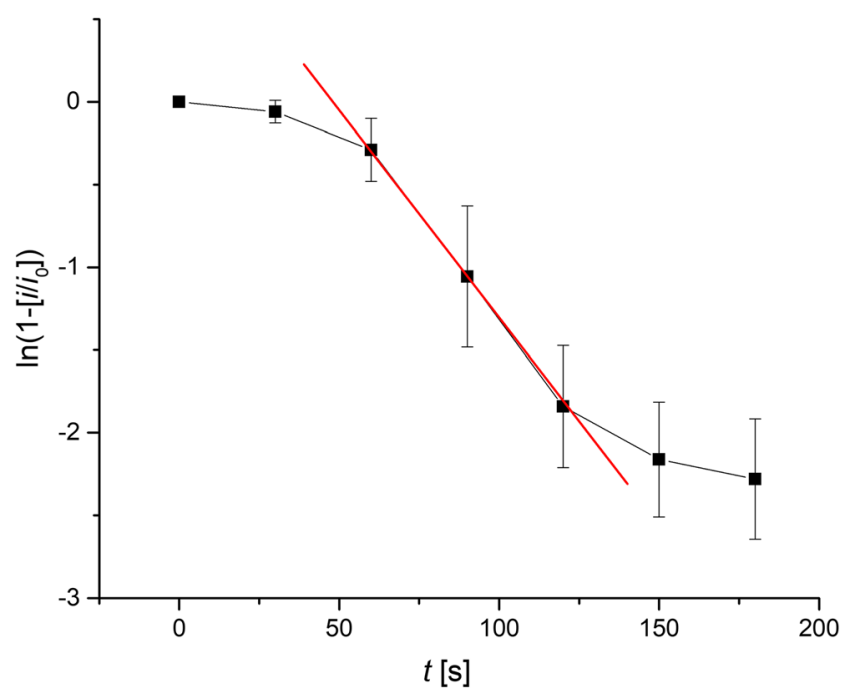

Fig. 2 Kinetics of the logarithmic inverse of the increase of the $\mathrm{Ru}$ $\left(\mathrm{NH}_{3}\right)_{6}^{3+}$ reduction signal $(i)$ at $\mathrm{C}_{10} \mathrm{SH}$ SAM-covered gold electrodes in dependence of the exposure time towards photolytically generated ROS from $1 \mathrm{mM} \mathrm{H}_{2} \mathrm{O}_{2}$

the experimental settings described, here. The mode of ROS generation, the applied thiol to form the SAM, the redox probe, and the employed $\mathrm{H}_{2} \mathrm{O}_{2}$ concentration used to generate ROS differed from the parameters reported by Hilgemann et al. [31]. We generated ROS photolytically instead of Fenton reaction to avoid additional elements (e.g., iron) in our experimental set-up and used $1 \mathrm{mM}$ instead of $500 \mathrm{mM}$ $\mathrm{H}_{2} \mathrm{O}_{2}$ to better mimic biologically relevant conditions. Therefore, the obtained SAM degradation curve differed slightly from the data reported before. For this low $\mathrm{H}_{2} \mathrm{O}_{2}$ concentration, the increase of the measured peak currents was low in the first $30 \mathrm{~s}$, followed by a time period with a faster increase of the peak currents. At longer treatment times, the increase of the peak currents with time slowed down again. We assume that the increase of currents measured within the first $30 \mathrm{~s}$ is lower because ROS mainly attacks the alkyl chains without exposing active gold sites. Then, the film degradation can take place as described by Hilgeman et al. for SAMs with shorter alkyl chains and higher ROS concentrations. However, using the linear part of the function $\ln \left[1-\left(i_{\mathrm{t}} / i_{0}\right)\right]$ vs. $t$ (see red line in Fig. 2) allows the comparison of the ROS scavenging potential of individual substances. For that purpose, the slope representing the SAM destruction rate in the presence of an antioxidant $\left(k_{\text {Aox }}\right)$ is compared with the rate of destruction in the absence of the antioxidant substance $(k)$ : scavenging $[\%]=\left[\frac{\left(k-k_{\text {Aox }}\right)}{k}\right] \times 100$

In Fig. 3, the impact of different concentrations of ascorbic acid on the regain of the $\mathrm{Ru}\left(\mathrm{NH}_{3}\right)_{6}^{3+}$ reduction signal at $\mathrm{C}_{10} \mathrm{SH}$ SAM-covered gold electrodes is shown. Ascorbic acid can slow down the degradation of the SAM by photolytically generated $\operatorname{ROS}\left(c\left(\mathrm{H}_{2} \mathrm{O}_{2}\right)=1 \mathrm{mM}\right)$ in a concentrationdependent manner, which is mirrored in the prolongation of 


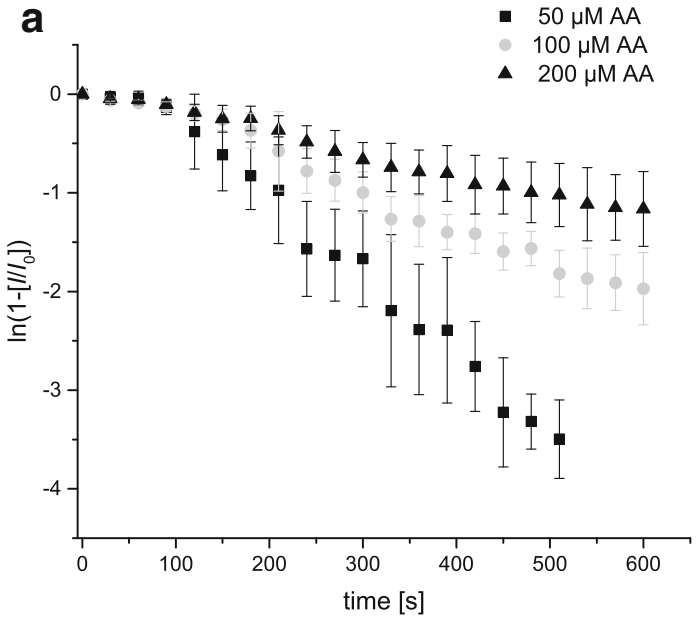

Fig. 3 a DPV currents $(I)$ measured at $\mathrm{C}_{10} \mathrm{SH}$ SAM-covered gold electrode in the presence of different concentrations of ascorbic acid plotted against the exposure times towards photolytically generated ROS from $1 \mathrm{mM} \mathrm{H}_{2} \mathrm{O}_{2}$. b Radical scavenging activity of different substances at a

the first plateau phase and decreased slopes of the curves in the linear region (Fig. 3a). The ability to scavenge ROS in this experimental setting differs between different substances (Fig. 3b). At a concentration of $100 \mu \mathrm{M}$, five different substances showed the following scavenging activities: ascorbic acid (AA) $82 \pm 3 \%$; caffeic acid (CA) $97 \%$; ferulic acid (FA) 75 $\pm 4 \%$; epigallocatechin gallate (EGCG) $94 \%$; Trolox $99 \%$ (Fig. 3a). Therefore, the ranking of the antioxidant activities is as follows: Trolox $>$ caffeic acid $(\mathrm{CA})>$ epigallocatechin gallate $($ EGCG) $>$ ascorbic acid (AA) $>$ ferulic acid (FA), (Fig. $3 b)$.

The radical scavenging activity depends on the ability to protect the SAM from structural damages that result in the loss of its insulating properties. This can either be achieved by direct interaction of the molecules with the UV light or radicals (hydroxyl radicals, superoxide) generated by the UV light or by interaction with secondary radical products that result from the first generation of radicals. Experiments were undertaken in aqueous media, while the $\mathrm{C}_{10} \mathrm{SH}$ SAM presents a more hydrophobic surface. In comparison with a lipid bilayer, the SAM lacks the hydrophilic head groups as well as embedded proteins that might alter its hydrophobicity. The antioxidant that performed best in this system was the water-soluble vitamin E derivate Trolox. In comparison with vitamin E, Trolox possesses the chroman head and the hydroxyl group that is associated with its radical scavenging activity but lacks the hydrocarbon tail. Therefore, similar radical scavenging activities have been reported for both molecules in aqueous media [31]. Since the radicals are produced within the aqueous phase, Trolox performs well in our system. Caffeic acid and EGCG have a high radical scavenging impact on the SAM degradation rate, as well. All three substances are also soluble in organic solvents [32-34]. On the other hand, the

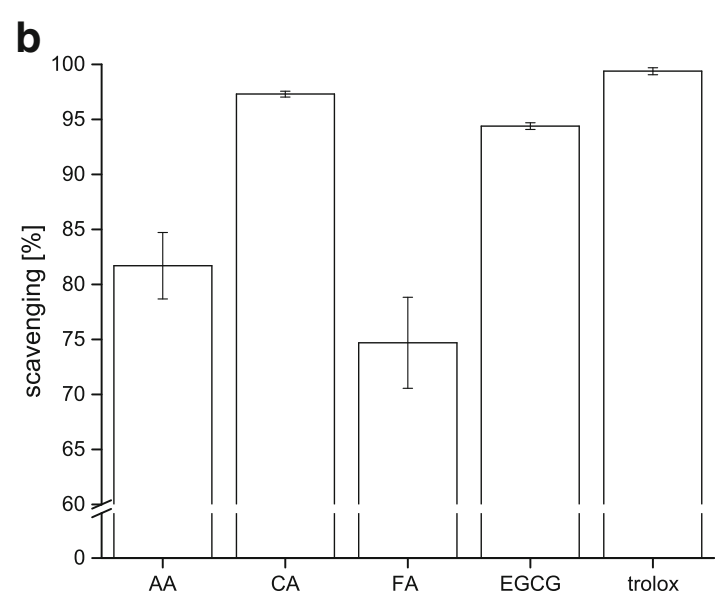

concentration of $100 \mu \mathrm{M}$ determined by their potential to decrease SAM degradation by ROS. AA ascorbic acid, CA caffeic acid, FA ferulic acid, EGCG epigallocatechin gallate

radical scavenging activity of ascorbic acid and ferulic acid, which are only soluble in water, is lower. This indicates that the assay might also asses to some extent the interaction of the substances with the lipophilic thiol molecules of the SAM. It has been reported before that Trolox is capable to interact with lipophilic structures [31] in a way that potentially also enables radical scavenging directly at the interface SAM/electrolyte solution. The results further indicate that direct absorption of UV light, which would also add to the measured radical scavenging activity, seems negligible for the investigated substances. If direct UV-light absorption would contribute significantly, we would expect more homogeneous scavenging activities for all investigated substances.

\section{Effect of reactive species on lipid bilayer}

Cyclic voltammetry was used to verify lipid bilayer formation at the gold electrode. $\mathrm{K}_{4}\left[\mathrm{Fe}(\mathrm{CN})_{6}\right]$ was chosen as the redox probe because it is a surface-sensitive probe and it has better passivation properties at the surface of the electrode after lipid bilayer formation compared with $\left[\mathrm{Ru}\left(\mathrm{NH}_{3}\right)_{6}\right] \mathrm{Cl}_{3}$ [30]. Moreover, the electron transfer between the solution species and the electrode must take place through bilayer defects [35]. For this purpose, cyclic voltammograms of $10 \mathrm{mM}$ $\mathrm{K}_{4}\left[\mathrm{Fe}(\mathrm{CN})_{6}\right]$ were measured before and after the formation of the bilayer on the gold electrode. According to the voltammogram (Fig. 4), oxidation and reduction peaks of the redox probe can be observed for the bare gold electrode and are lost after the formation of the lipid bilayer, indicating that it completely covers the electrode. After exposing the lipid bilayer to cold physical plasma-generated reactive species, their impact was monitored after subsequent replacement of the treated liquid by the redox probe solution. The results of the 


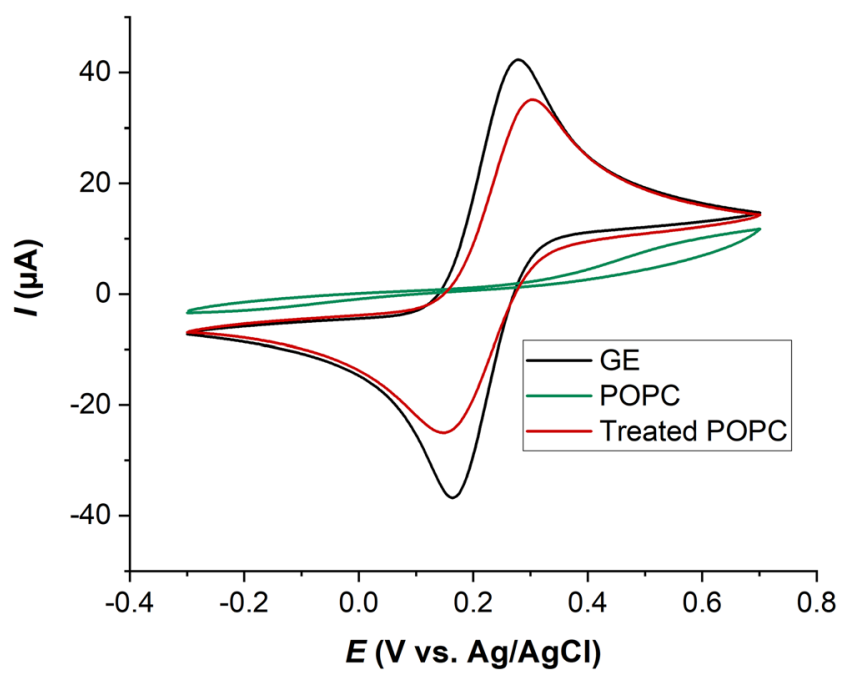

Fig. 4 Cyclic voltammograms of $10 \mathrm{mM} \mathrm{K} 4\left[\mathrm{Fe}(\mathrm{CN})_{6}\right]$ in $50 \mathrm{mM}$ phosphate buffer of gold electrode (GE), before (POPC) and after (treated POPC) 30-min plasma treatment of lipid bilayer

voltammetry (Fig. 4) showed the oxidative degradation of the lipid bilayer by restoring the initially present oxidation and reduction peaks of the redox system. However, similar to the SAM experiments, the original current of the bare gold electrode was not reached again after the treatment of the lipid bilayer.

\section{Protection effect of lipid bilayer by antioxidants during plasma treatments}

Differential pulse voltammetry (DPV) as a more sensitive voltammetry technique was used to study the protective effect of the lipid bilayer by different antioxidants during plasma treatments. Ascorbic acid (AA), caffeic acid (CA), epigallocatechin gallate (EGCG), and Trolox were used as antioxidants in this study. According to DPV voltammograms (Fig. 5 ), in the presence of antioxidants, an attenuated restoration of the oxidation peak was registered. $200 \mu \mathrm{M}$ EGCG showed a complete protection against CPP-derived reactive species, but at lower concentrations of EGCG $(50 \mu \mathrm{M})$ oxidative damage of the SAM recurred. As can be seen in Fig. 5, the passivation of the electrode surface is even better in the case of high concentrations of EGCG compared with the lipid bilayer. The same was found for Trolox at high concentrations. We assume that both antioxidants are distributed on the surface of the lipid bilayer, leading to an additional blocking of the electron transfer. In addition, the results showed a positive potential shift with increasing antioxidant activity in the system and a decrease in the peak current of the redox probe. The positive potential shift is due to less defect formation in the lipid bilayer and slow electron transfer between the redox probe and surface of electrode. The results also indicated that Trolox has maximum antioxidant activity in this study.

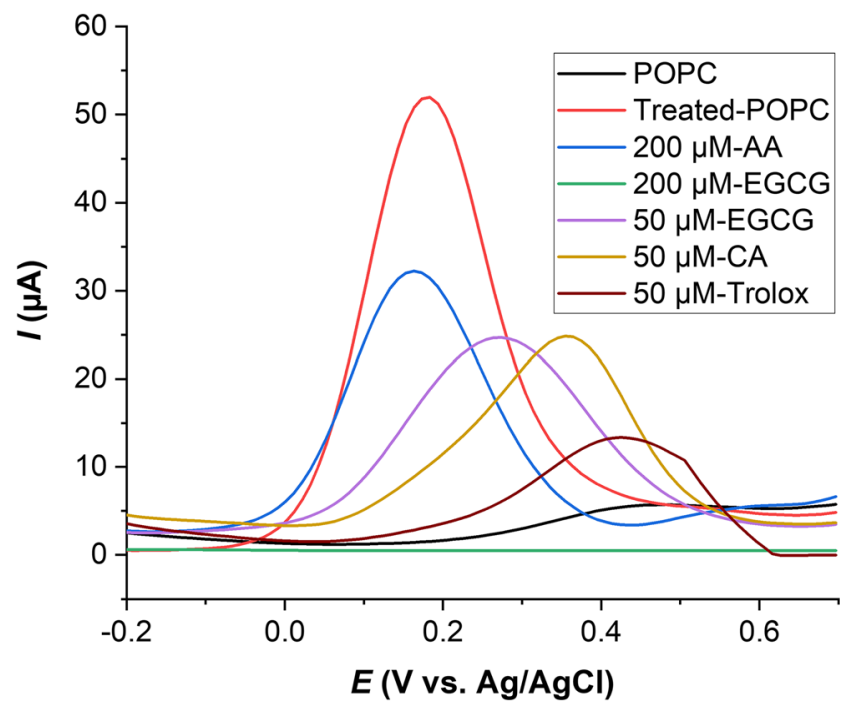

Fig. 5 Differential pulse voltammograms of $10 \mathrm{mM} \mathrm{K}_{4}\left[\mathrm{Fe}(\mathrm{CN})_{6}\right]$ in $50 \mathrm{mM}$ phosphate buffer after 30-min plasma treatments of a lipid bilayer with and without different antioxidants. AA ascorbic acid, CA caffeic acid, EGCG epigallocatechin gallate, Trolox

In addition, the percentage of the protective effect of antioxidants was calculated using the following equation:

$\%$ Protection effect $=\left[\left(i_{1}-i_{2}\right) / i_{1}\right] \times 100$

where $i_{1}$ and $i_{2}$ are the electrochemical currents obtained after plasma treatment of lipid bilayer without and with antioxidants, respectively. As shown in (Fig. 6), a protective effect of $71 \pm 3 \%, 54 \pm 5 \%, 49 \pm 1 \%, 100 \%$, and $32 \pm 4 \%$ was observed for Trolox $(50 \mu \mathrm{M})$, caffeic acid $(50 \mu \mathrm{M})$, EGCG $(50 \mu \mathrm{M})$, EGCG $(200 \mu \mathrm{M})$, and ascorbic acid $(200 \mu \mathrm{M})$, respectively.

Furthermore, the electrochemical parameters of the redox system for plasma treatment of the lipid bilayer in the presence

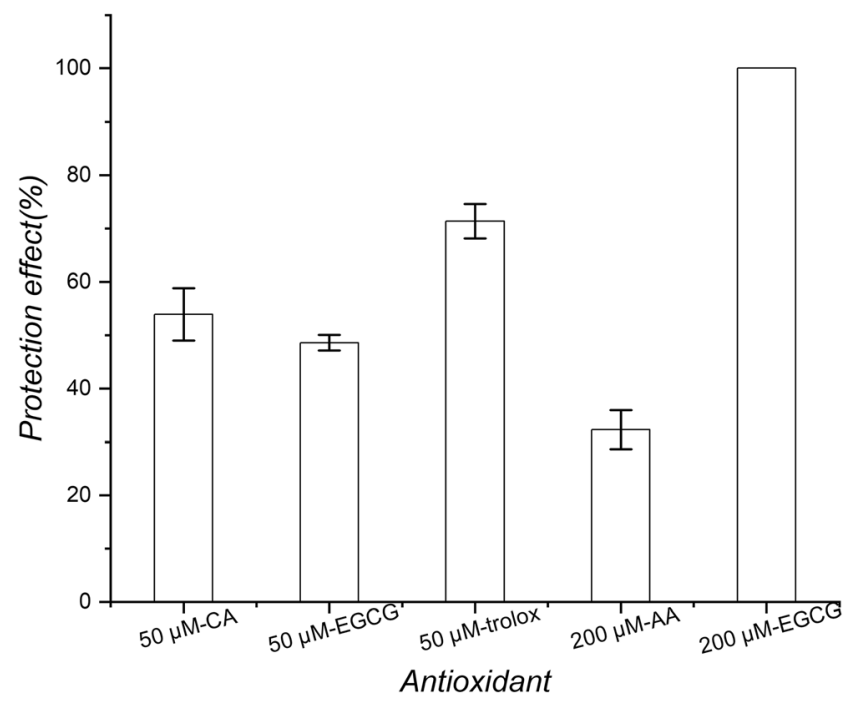

Fig. 6 Comparison of the protective effect of different antioxidants during plasma treatment of lipid bilayer 
Table 1 Electrochemical parameters of $10 \mathrm{mM}$ $\mathrm{K}_{4}\left[\mathrm{Fe}(\mathrm{CN})_{6}\right]$ in $50 \mathrm{mM}$ phosphate buffer at bare gold electrode, and for lipid bilayer modified gold electrode after 30min plasma treatment in presence of different antioxidants

\begin{tabular}{llll}
\hline & $I_{\mathrm{ox}}(\mu \mathrm{A}) \pm \mathrm{SD}$ & $I_{\mathrm{red}}(\mu \mathrm{A}) \pm \mathrm{SD}$ & $\Delta E(\mathrm{mV}) \pm \mathrm{SD}$ \\
\hline $200 \mu \mathrm{M}$ ascorbic acid & $21.6 \pm 0.3$ & $19.7 \pm 0.3$ & $173 \pm 6$ \\
$200 \mu \mathrm{M}$ EGCG & - & - & - \\
$200 \mu \mathrm{M}$ caffeic acid & - & - & - \\
$200 \mu \mathrm{M}$ Trolox & - & - & $262 \pm 39$ \\
$50 \mu \mathrm{M}$ EGCG & $16.9 \pm 2.0$ & $16.5 \pm 1.3$ & $392 \pm 15$ \\
$50 \mu \mathrm{M}$ caffeic acid & $16.0 \pm 0.7$ & $10.5 \pm 2.2$ & $640 \pm 45$ \\
$50 \mu \mathrm{M}$ Trolox & $5.9 \pm 1.1$ & $4.3 \pm 1.5$ & $148 \pm 5$ \\
Absence of antioxidants & $28.9 \pm 1.0$ & $27.1 \pm 1.0$ & $142 \pm 16$ \\
Gold electrode & $39.1 \pm 2.7$ & $39.6 \pm 2.0$ & \\
\hline
\end{tabular}

of antioxidants were investigated by means of cyclic voltammetry. The results showed (Table 1) an increase in peak separation and a decrease in peak currents of the redox system in the presence of antioxidants, confirming the slow electron transfer between the redox probe and the surface of the gold electrode, and the reduction of defect formation in the lipid bilayer in the presence of antioxidants. The results also confirm the DPV data, verifying Trolox to have the maximum antioxidant activity in this study. Therefore, the order of radical scavenging activity of the antioxidant to protect the lipid bilayer from reactive species is as follows: Trolox $>\mathrm{CA}>$ EGCG > AA. According to the results, Trolox showed the maximum protective effect in this study. As we discussed at the SAM part, the structure of Trolox consists of a carboxyl group connected to a chroman ring, and due to a similar structure of Trolox and vitamin E, several studies have reported that Trolox is able to partially diffuse into the lipid bilayer [36, 37]. Therefore, in addition to its hydrophilic antioxidant activity, it can also partially act as a lipophilic antioxidant. However, the diffusion of Trolox in the lipid bilayer depends on the structure of the bilayer and also on the presence of cholesterol and sphingomyelin lipids at the membrane [38]. In the current work, the lipid bilayer is neutral due to the positive charge of the choline group and the negative charge of the phosphate group. Under such conditions, the negative charge of the carboxyl group in the Trolox leads to electrostatic interactions with the choline group of the lipid bilayer. This distribution of the Trolox on the surface of the bilayer is sufficient to meet the reactive species and thus terminate the peroxidation process of the lipid bilayer [31].

\section{Conclusions}

In this work, a gold-based self-assembled monolayer was used to study the radical scavenging activity of various antioxidants against reactive species. The results were compared with the data obtained using a gold-supported lipid bilayer as a model for a cell membrane. In addition, photolysis of hydrogen peroxide and plasma treatment of water was used to generate short-lived reactive species as cellular free radicals. DPV and $\mathrm{CV}$ measurements confirmed the oxidative damage at both sensors by reactive species and showed the ability of antioxidants as scavengers to protect SAM and lipid bilayers from free radicals. Interestingly, a similar order of radical scavenger activity was obtained for both electrochemical sensors. The protective effect depends on the structure of the antioxidants and also on the interaction between the antioxidant and the sensors. As Trolox has a maximum of antioxidant activity, this could be due to the structure of Trolox as a watersoluble analog of vitamin E. Because of the amphiphilic behavior, it can interact with the SAM and the lipid bilayer at the surface to the electrolyte, and it can also partially diffuse into the lipid bilayer to protect it from reactive species. In addition to the similarity of the SAM electrode to the POPC model membrane in the assessment of antioxidants, the stability, robustness, and simple fabrication of these sensors offer unique advantages. To conclude, the electrochemical assay based on SAM electrode is an alternative to similar antioxidants assessment based on electrochemical sensors, which often suffer from limited stability, high costs, and the inability to function outside their optimal conditions.

Funding information Open Access funding provided by Projekt DEAL. This work was funded by the Deutsche Forschungsgemeinschaft (DFG, German Research Foundation) 231396381/GRK1947. K.W. was financially supported by the German Federal Ministry of Education and Research (grant number 03Z22DN12).

Open Access This article is licensed under a Creative Commons Attribution 4.0 International License, which permits use, sharing, adaptation, distribution and reproduction in any medium or format, as long as you give appropriate credit to the original author(s) and the source, provide a link to the Creative Commons licence, and indicate if changes were made. The images or other third party material in this article are included in the article's Creative Commons licence, unless indicated otherwise in a credit line to the material. If material is not included in the article's Creative Commons licence and your intended use is not permitted by statutory regulation or exceeds the permitted use, you will need to obtain permission directly from the copyright holder. To view a copy of this licence, visit http://creativecommons.org/licenses/by/4.0/. 


\section{References}

1. Valko M, Leibfritz D, Moncol J, Cronin MT, Mazur M, Telser J (2007) Free radicals and antioxidants in normal physiological functions and human disease. Int J Biochem Cell Biol 39(1):44-84. https://doi.org/10.1016/j.biocel.2006.07.001

2. Christelle Martine A, Yvan L, Daniele E (2010) Dietary antioxidants and oxidative stress from a human and plant perspective: a review. Current Nutrition \& Food Science 6(1):2-12. https://doi. org/10.2174/157340110790909563

3. Nothlings U, Murphy SP, Wilkens LR, Henderson BE, Kolonel LN (2007) Flavonols and pancreatic cancer risk: the multiethnic cohort study. Am J Epidemiol 166(8):924-931. https://doi.org/10.1093/ aje/kwm172

4. Berger A, Venturelli S, Kallnischkies M, Bocker A, Busch C, Weiland T, Noor S, Leischner C, Weiss TS, Lauer UM, Bischoff SC, Bitzer M (2013) Kaempferol, a new nutrition-derived pan-inhibitor of human histone deacetylases. J Nutr Biochem 24(6):977985. https://doi.org/10.1016/j.jnutbio.2012.07.001

5. Yan H, Wang X, Niu J, Wang Y, Wang P, Liu Q (2014) Anticancer effect and the underlying mechanisms of gypenosides on human colorectal cancer SW-480 cells. PLoS One 9(4):e95609. https://doi.org/10.1371/journal.pone.0095609

6. Bendary E, Francis RR, Ali HMG, Sarwat MI, El Hady S (2013) Antioxidant and structure-activity relationships (SARs) of some phenolic and anilines compounds. Annals of Agricultural Sciences 58(2):173-181. https://doi.org/10.1016/j.aoas.2013.07. 002

7. Miller NJ, Rice-Evans C, Davies MJ, Gopinathan V, Milner A (1993) A novel method for measuring antioxidant capacity and its application to monitoring the antioxidant status in premature neonates. Clin Sci (Lond) 84(4):407-412. https://doi.org/10.1042/ $\operatorname{cs} 0840407$

8. Benzie IF, Strain JJ (1996) The ferric reducing ability of plasma (FRAP) as a measure of "antioxidant power": the FRAP assay. Anal Biochem 239(1):70-76. https://doi.org/10.1006/abio.1996. 0292

9. Blois MS (1958) Antioxidant determinations by the use of a stable free radical. Nature 181(4617):1199-1200. https://doi.org/10.1038/ $1811199 \mathrm{a} 0$

10. Muff J, Bennedsen LR, Sogaard EG (2011) Study of electrochemical bleaching of p-nitrosodimethylaniline and its role as hydroxyl radical probe compound. Journal of Applied Electrochemistry 41(5):599-607. https://doi.org/10.1007/s10800-011-0268-1

11. Popov I, Lewin G (1999) Antioxidative homeostasis: characterization by means of chemiluminescent technique. Methods Enzymol 300:437-456. https://doi.org/10.1016/s0076-6879(99)00149-4

12. Fogliano V, Verde V, Randazzo G, Ritieni A (1999) Method for measuring antioxidant activity and its application to monitoring the antioxidant capacity of wines. J Agric Food Chem 47(3):10351040. https://doi.org/10.1021/jf980496s

13. Cao G, Alessio HM, Cutler RG (1993) Oxygen-radical absorbance capacity assay for antioxidants. Free Radic Biol Med 14(3):303311. https://doi.org/10.1016/0891-5849(93)90027-r

14. Horakova L, Schaur RJ, Balgavy P (1996) The crocin assay for the determination of relative rate constants of alkoxyl radical reactions with the pyridoindole stobadine and with other antioxidants. Redox Rep 2(6):401-405. https://doi.org/10.1080/13510002.1996. 11747081

15. Ceriello A, Bortolotti N, Falleti E, Taboga C, Tonutti L, Crescentini A, Motz E, Lizzio S, Russo A, Bartoli E (1997) Total radicaltrapping antioxidant parameter in NIDDM patients. Diabetes Care 20(2):194-197. https://doi.org/10.2337/diacare.20.2.194

16. Hotta H, Nagano S, Ueda M, Tsujino Y, Koyama J, Osakai T (2002) Higher radical scavenging activities of polyphenolic antioxidants can be ascribed to chemical reactions following their oxidation. Biochimica Et Biophysica Acta-General Subjects 1572(1):123-132. https://doi.org/10.1016/S0304-4165(02)002854

17. Rene A, Abasq ML, Hauchard D, Hapiot P (2010) How do phenolic compounds react toward superoxide ion? A simple electrochemical method for evaluating antioxidant capacity. Anal Chem 82(20): 8703-8710. https://doi.org/10.1021/ac101854w

18. Cren-Olive C, Hapiot P, Pinson J, Rolando C (2002) Free radical chemistry of flavan-3-ols: determination of thermodynamic parameters and of kinetic reactivity from short (ns) to long (ms) time scale. J Am Chem Soc 124(47):14027-14038. https://doi.org/10.1021/ ja0262434

19. Andrieux CP, Hapiot P, Saveant JM (1987) Mechanism of superoxide ion disproportionation in aprotic-solvents. Journal of the American Chemical Society 109(12):3768-3775. https://doi.org/ $10.1021 / \mathrm{ja} 00246 \mathrm{a} 040$

20. Tammeveski K, Tenno TT, Mashirin AA, Hillhouse EW, Manning P, McNeil CJ (1998) Superoxide electrode based on covalently immobilized cytochrome c: modelling studies. Free Radic Biol Med 25(8):973-978. https://doi.org/10.1016/s0891-5849(98) 00182-8

21. Beissenhirtz MK, Scheller FW, Lisdat F (2004) A superoxide sensor based on a multilayer cytochrome c electrode. Anal Chem 76(16):4665-4671. https://doi.org/10.1021/ac049738f

22. Tian Y, Mao L, Okajima T, Ohsaka T (2002) Superoxide dismutase-based third-generation biosensor for superoxide anion. Anal Chem 74(10):2428-2434. https://doi.org/10.1021/ac0157270

23. Campanella L, Favero G, Persi L, Tomassetti M (2000) New biosensor for superoxide radical used to evidence molecules of biomedical and pharmaceutical interest having radical scavenging properties. J Pharm Biomed Anal 23(1):69-76. https://doi.org/10. 1016/s0731-7085(00)00276-4

24. Scholz F, Lopez de Lara Gonzalez G, Machado de Carvalho L, Hilgemann M, Brainina KZ, Kahlert H, Jack RS, Minh DT (2007) Indirect electrochemical sensing of radicals and radical scavengers in biological matrices. Angew Chem Int Ed Engl 46(42): 8079-8081. https://doi.org/10.1002/anie.200702690

25. Hilgemann M, Scholz F, Kahlert H, de Carvalho LM, da Rosa MB, Lindequist U, Wurster M, do Nascimento PC, Bohrer D (2010) Electrochemical assay to quantify the hydroxyl radical scavenging activity of medicinal plant extracts. Electroanalysis 22(4):406-412. https://doi.org/10.1002/elan.200900385

26. Martensson C, Agmo Hernandez V (2012) Ubiquinone-10 in goldimmobilized lipid membrane structures acts as a sensor for acetylcholine and other tetraalkylammonium cations. Bioelectrochemistry 88:171-180. https://doi.org/10.1016/j. bioelechem.2012.03.009

27. Burgess I, Li M, Horswell SL, Szymanski G, Lipkowski J, Majewski J, Satija S (2004) Electric field-driven transformations of a supported model biological membrane-an electrochemical and neutron reflectivity study. Biophys J 86(3):1763-1776. https://doi. org/10.1016/S0006-3495(04)74244-7

28. Thal D, Kahlert H, Chinnaya J, Ahrens P, Hasse U (2018) Impact of gold-1-decanethiol-SAM formation and removal cycles on the surface properties of polycrystalline gold and SAM quality. Journal of Solid State Electrochemistry 22(4):1149-1154. https://doi.org/10. 1007/s10008-017-3858-y

29. Reuter S, von Woedtke T, Weltmann KD (2018) The kINPen-a review on physics and chemistry of the atmospheric pressure plasma jet and its applications. Journal of Physics D-Applied Physics 51(23). https://doi.org/10.1088/1361-6463/aab3ad

30. Wilke N, Baruzzi AM (2002) Comparative analysis of the charge transfer processes of the $\mathrm{Ru}(\mathrm{NH} 3) 63+/ \mathrm{Ru}(\mathrm{NH} 3) 62+$ and $\mathrm{Fe}(\mathrm{CN}) 63$ $-/ \mathrm{Fe}(\mathrm{CN}) 64-$ redox couples on glassy carbon electrodes modified 
by different lipid layers. Journal of Electroanalytical Chemistry 537(1):67-76. https://doi.org/10.1016/S0022-0728(02)01249-4

31. Lucio M, Nunes C, Gaspar D, Ferreira H, Lima JLFC, Reis S (2009) Antioxidant activity of vitamin $\mathrm{E}$ and Trolox: understanding of the factors that govern lipid peroxidation studies in vitro. Food Biophysics 4(4):312-320. https://doi.org/10.1007/s11483-0099129-4

32. Islam MZ, Cho DK, Lee YT (2020) Bioactive compounds and antioxidant capacity of tea infusion prepared from whole and ground medicinal herb parts. Cyta-Journal of Food 18(1):116121. https://doi.org/10.1080/19476337.2019.1702104

33. Ji WQ, Meng QQ, Ding L, Wang F, Dong JJ, Zhou GY, Wang BH (2016) Measurement and correlation of the solubility of caffeic acid in eight mono and water plus ethanol mixed solvents at temperatures from (293.15 to 333.15) K. Journal of Molecular Liquids 224: 1275-1281. https://doi.org/10.1016/j.molliq.2016.10.110

34. Esmaeelpanah E, Razavi BM, Vahdati Hasani F, Hosseinzadeh H (2018) Evaluation of epigallocatechin gallate and epicatechin gallate effects on acrylamide-induced neurotoxicity in rats and cytotoxicity in PC 12 cells. Drug Chem Toxicol 41(4):441-448. https:// doi.org/10.1080/01480545.2017.1381108

35. Barroso MF, Luna MA, Moyano F, Delerue-Matos C, Correa NM, Molina PG (2018) Study of lipid peroxidation and ascorbic acid protective role in large unilamellar vesicles from a new electrochemical performance. Bioelectrochemistry 120:120-126. https:// doi.org/10.1016/j.bioelechem.2017.12.003

36. Sagach VF, Scrosati M, Fielding J, Rossoni G, Galli C, Visioli F (2002) The water-soluble vitamin E analogue Trolox protects against ischaemia/reperfusion damage in vitro and ex vivo. A with vitamin E. Pharmacol Res 45(6):435-439. https://doi.org/10.1006/ phrs.2002.0993

37. Barclay LRC, Artz JD, Mowat JJ (1995) Partitioning and antioxidant action of the water-soluble antioxidant, Trolox, between the aqueous and lipid phases of phosphatidylcholine membranes - C-14 tracer and product studies. Bba-Biomembranes 1237(1):77-85. https://doi.org/10.1016/0005-2736(95)00071-A

38. Saha S, Panieri E, Suzen S, Saso L (2020) The Interaction of flavonols with membrane components: potential effect on antioxidant activity. J Membr Biol 253(1):57-71. https://doi.org/10.1007/ s00232-019-00105-1

Publisher's note Springer Nature remains neutral with regard to jurisdictional claims in published maps and institutional affiliations. 